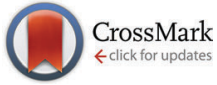

Cite this: Phys. Chem. Chem. Phys., $2016,18,17253$

Received 12th February 2016, Accepted 5th April 2016

DOI: $10.1039 / \mathrm{c} 6 \mathrm{cp} 00967 \mathrm{k}$

www.rsc.org/pccp

\title{
Different routes to methanol: inelastic neutron scattering spectroscopy of adsorbates on supported copper catalysts
}

\author{
Timur Kandemir, ${ }^{a}$ Matthias Friedrich, ${ }^{a}$ Stewart F. Parker, ${ }^{b}$ Felix Studt, \\ David Lennon, ${ }^{d}$ Robert Schlögl ${ }^{a}$ and Malte Behrens*e
}

\begin{abstract}
We have investigated methanol synthesis with model supported copper catalysts, $\mathrm{Cu} / \mathrm{ZnO}$ and $\mathrm{Cu} / \mathrm{MgO}$, using $\mathrm{CO} / \mathrm{H}_{2}$ and $\mathrm{CO}_{2} / \mathrm{H}_{2}$ as feedstocks. Under $\mathrm{CO} / \mathrm{H}_{2}$ both catalysts show chemisorbed methoxy as a stable intermediate, the $\mathrm{Cu} / \mathrm{MgO}$ catalyst also shows hydroxyls on the support. Under $\mathrm{CO}_{2} / \mathrm{H}_{2}$ the catalysts behave differently, in that formate is also seen on the catalyst. For the $\mathrm{Cu} / \mathrm{ZnO}$ catalyst hydroxyls are present on the metal whereas for the $\mathrm{Cu} / \mathrm{MgO}$ hydroxyls are found on the support. These results are consistent with a recently published model for methanol synthesis and highlight the key role of $\mathrm{ZnO}$ in the process.
\end{abstract}

\section{Introduction}

In commercial low-pressure methanol synthesis $\mathrm{Cu} / \mathrm{ZnO} / \mathrm{Al}_{2} \mathrm{O}_{3}$ catalysts have been successfully used for more than 50 years to convert synthesis gas $\left(\mathrm{H}_{2}, \mathrm{CO}, \mathrm{CO}_{2}\right)$ into methanol due to their high activity and excellent stability under typical reaction conditions of $250{ }^{\circ} \mathrm{C}$ and 50-100 bar. Despite the successful application of this catalyst and the development of promising $\mathrm{Cu}$-based catalysts on a variety of different oxide supports ${ }^{1-4}$ the exact mechanism of this reaction is still not fully understood. In the past years, considerable efforts were made by experimentalists and theoreticians to elucidate the reaction mechanism and active center of methanol synthesis over conventional and the newly developed Cu-based catalysts. ${ }^{5-7}$ Work from the late 1970's proposed CO hydrogenation (eqn (1))

$$
\mathrm{CO}+2 \mathrm{H}_{2} \rightarrow \mathrm{CH}_{3} \mathrm{OH}
$$

as the primary reaction pathway for methanol synthesis ${ }^{8,9}$ until isotope labeling experiments identified $\mathrm{CO}_{2}$ as the main carbon source according to eqn (2)

$$
\mathrm{CO}_{2}+3 \mathrm{H}_{2} \rightarrow \mathrm{CH}_{3} \mathrm{OH}+\mathrm{H}_{2} \mathrm{O}
$$

\footnotetext{
${ }^{a}$ Abteilung Anorganische Chemie, Fritz-Haber-Institut der Max-Planck-Gesellschaft, Faradayweg 4-6, 14195 Berlin, Germany

${ }^{b}$ ISIS Facility, STFC Rutherford Appleton Laboratory, Chilton, Didcot, Oxfordshire, OX11 OQX, UK

${ }^{c}$ SUNCAT Center for Interface Science and Catalysis, SLAC National Accelerator Laboratory, 2575 Sand Hill Road, Menlo Park, CA 94025, USA

${ }^{d}$ School of Chemistry, Joseph Black Building, University of Glasgow, Glasgow, G12 8QQ, UK

${ }^{e}$ Faculty of Chemistry and CENIDE, University of Duisburg-Essen, Universitätsstr. 7, 45141 Essen, Germany. E-mail: malte.behrens@uni-due.de
}

formed by the water gas shift reaction ${ }^{10,11}$ (eqn (3))

$$
\mathrm{CO}+\mathrm{H}_{2} \mathrm{O} \rightarrow \mathrm{CO}_{2}+\mathrm{H}_{2} .
$$

In accordance with this finding, the great majority of state-ofthe-art methanol synthesis plants derive their synthesis gas from reforming or partial oxidation of natural gas close to stoichiometric composition with respect to formation of the end-product (i.e. $\mathrm{CO}_{2}$ : $\mathrm{CO}$ ratio $\left.1: 0.75\right) .{ }^{12,13}$ In the last few years, in addition to fossil-derived synthesis gas, also nonfossil synthesis gas received increasing attention, i.e. CO-rich gas derived from biomass gasification processes $\left(\mathrm{CO}_{2}: \mathrm{CO}\right.$ ratio $\sim 0.75: 1),{ }^{14}$ or the hydrogenation of pure anthropogenic $\mathrm{CO}_{2}$ with "green" $\mathrm{H}_{2}$ derived from excess energy from renewable resources. ${ }^{13}$ Some of the authors recently published a model of the active site and proposed bi-metallic stepped facets, such as $\mathrm{CuZn}(211)$, as the $\mathrm{CO}_{2}$-converting centers, ${ }^{6,15}$ emphasizing the crucial role for $\mathrm{Zn}$ as a component of the active surface ensemble, which has been observed and debated in many previous literature reports.

Within this study and many others, formate (HCOO) was identified as a very stable reaction intermediate in the hydrogenation of $\mathrm{CO}_{2}$ (eqn (2)) via the formation of $\mathrm{HCOOH}$ (eqn (6)) and $\mathrm{H}_{2} \mathrm{COOH}$ (eqn (7)) according to the following scheme: ${ }^{5}$

$$
\begin{gathered}
\mathrm{H}_{2}(\mathrm{~g})+2^{*} \leftrightarrow 2 \mathrm{H}^{*} \\
\mathrm{CO}_{2}(\mathrm{~g})+\mathrm{H}^{*} \leftrightarrow \mathrm{HCOO}^{*} \\
\mathrm{HCOO}^{*}+\mathrm{H}^{*} \leftrightarrow \mathrm{HCOOH}^{*}+{ }^{*} \\
\mathrm{HCOOH}^{*}+\mathrm{H}^{*} \leftrightarrow \mathrm{H}_{2} \mathrm{COOH}^{*}+* \\
\mathrm{H}_{2} \mathrm{COOH}^{*}+* \leftrightarrow \mathrm{H}_{2} \mathrm{CO}^{*}+\mathrm{OH}^{*}
\end{gathered}
$$




$$
\begin{aligned}
& \mathrm{H}_{2} \mathrm{CO}^{*}+\mathrm{H}^{*} \leftrightarrow \mathrm{H}_{3} \mathrm{CO}^{*}+{ }^{*} \\
& \mathrm{H}_{3} \mathrm{CO}^{*}+\mathrm{H}^{*} \leftrightarrow \mathrm{CH}_{3} \mathrm{OH}(\mathrm{g})+2^{*} \\
& \mathrm{OH}^{*}+\mathrm{H}^{*} \leftrightarrow \mathrm{H}_{2} \mathrm{O}(\mathrm{g})+2^{*} \\
& \mathrm{CO}(\mathrm{g})+* \leftrightarrow \mathrm{CO}^{*} \\
& \mathrm{CO}^{*}+\mathrm{H}^{*} \leftrightarrow \mathrm{HCO}^{*}+* \\
& \mathrm{HCO}^{*}+\mathrm{H}^{*} \leftrightarrow \mathrm{H}_{2} \mathrm{CO}^{*}+*
\end{aligned}
$$

The strong interaction of formate with the $\mathrm{Cu}$ surface was explained by Grabow et al. by its very high binding energy of $-2.68 \mathrm{eV}$ for the $\mathrm{Cu}(111)$ facet. $^{5}$ On the (211) surface, the binding was found to be even stronger ${ }^{6}$ rendering formate a very stable species on highly active surfaces and suggesting the further hydrogenation of formate to methoxy and methanol to be the rate-determining step in methanol synthesis from $\mathrm{CO}_{2}$ over the industrial $\mathrm{Cu} / \mathrm{ZnO} / \mathrm{Al}_{2} \mathrm{O}_{3}$ catalysts. $^{12,15,16}$ The surface $\mathrm{OH}$ groups and the final product have lower binding energies and are removed as water $\left(\mathrm{BE}_{\mathrm{Cu}(111)}=-0.21 \mathrm{eV}\right)$ and methanol $\left(\mathrm{BE}_{\mathrm{Cu}(111)}=-0.28 \mathrm{eV}\right) \cdot{ }^{5}$ Again, DFT calculations have revealed a further increase of the adsorption strength also of other intermediates such as $\mathrm{H}_{2} \mathrm{COOH}$ and $\mathrm{H}_{3} \mathrm{CO}$ by alloying of $\mathrm{Zn}$ into the $\mathrm{Cu}$-nanoparticles surface steps, ${ }^{6,15}$ one aspect of the hotly debated $\mathrm{Cu}-\mathrm{ZnO}$ synergy. ${ }^{12}$

The evolution of such bimetallic, stepped surface facets is believed to be the result of a strong metal-support interaction (SMSI). ${ }^{17,18}$ For the industrial catalyst systems, indeed a pronounced $\mathrm{Zn}$ enrichment at the surface of the catalyst was observed by depth-sensitive XPS measurements, ${ }^{2}$ while no alloy formation in the bulk was observable under conventional synthesis conditions of $250{ }^{\circ} \mathrm{C}$ and 60 bar. ${ }^{19}$ This situation is different for catalytic systems, which contain $\mathrm{MgO}$ rather than $\mathrm{ZnO}$ as the oxide support. In earlier experiments, $\mathrm{Cu} / \mathrm{MgO}$ catalysts showed a significant activity in $\mathrm{CO} / \mathrm{H}_{2}$ containing feed gases. ${ }^{1}$ These results were more recently confirmed by laboratory performance studies carried out at $230{ }^{\circ} \mathrm{C}$ and 30 bar with a highly active $\mathrm{Cu} / \mathrm{MgO}$ catalyst in $\mathrm{CO} / \mathrm{H}_{2}$ feed gas. ${ }^{2}$ XPS depthprofiling experiments carried out on this catalyst revealed a $\mathrm{Mg}$ enrichment at the very outermost catalyst surface, but a generally much lower tendency of overlayer formation compared to $\mathrm{Cu} / \mathrm{ZnO}$, which was attributed to the weaker metal-oxide interaction owing to the less reducible nature of $\mathrm{MgO}^{2}$ Considering that $\mathrm{Cu} / \mathrm{MgO}$ is a very good $\mathrm{CO}$ hydrogenation catalyst, while $\mathrm{Cu} / \mathrm{ZnO}$ is preferably hydrogenating $\mathrm{CO}_{2}$, the results indicate that the oxide support does not act only as a structural promoter, but also plays a determining role in the preferred pathway for the two routes of methanol synthesis from $\mathrm{CO}_{2} / \mathrm{H}_{2}$ or $\mathrm{CO} / \mathrm{H}_{2}$ as the carbon source..$^{1,2,15}$ In the many spectroscopic studies performed on $\mathrm{Cu},{ }^{20,21} \mathrm{ZnO}^{22}$ or $\mathrm{Cu} / \mathrm{ZnO}^{23-25} /\left(\mathrm{Al}_{2} \mathrm{O}_{3}\right)^{26}$ in its unreduced ${ }^{27}$ or operational state ${ }^{28}$ the most abundant surface species found were formyl, methoxy and formate. ${ }^{12}$

In this work, we investigate the role of the oxide support of catalysts for methanol synthesis and in particular test the working hypothesis that methanol formation occurs through different mechanisms and intermediates depending on whether $\mathrm{Zn}$ is present or absent. For this purpose, we have prepared a conventional $\mathrm{Al}_{2} \mathrm{O}_{3}$-promoted $\mathrm{Cu} / \mathrm{ZnO}(\mathrm{CZ})$ catalyst and a $\mathrm{Cu} / \mathrm{MgO}$ catalyst without $\mathrm{ZnO}(\mathrm{CM})$, operated them both in $\mathrm{CO} / \mathrm{H}_{2}$ and $\mathrm{CO}_{2} / \mathrm{H}_{2}$ syngas feeds and studied the post-reaction surface adsorbates by inelastic neutron scattering (INS) using the MAPS spectrometer ${ }^{29}$ at the ISIS Facility of the STFC Rutherford Appleton Laboratory. In contrast to comparable methods (e.g. FT-IR, DRIFTS), INS can be readily used on realistic nanostructured and black catalysts, probes a representatively large sample of $c a .20 \mathrm{~g}$, furthermore it exhibits high sensitivity towards hydrogen-containing adsorbates on the catalyst across the entire mid-infrared, 0-4000 $\mathrm{cm}^{-1}$, range. The successful application of this method for catalyst characterization was formerly demonstrated by the groups of Albers, Lennon and Parker. ${ }^{30-34}$

\section{Experimental}

The catalytic reactions were carried out on previously described ${ }^{18}$ gas handling system that is designed to provide the large samples needed for INS spectroscopy. Approximately $35 \mathrm{~g}$ of the catalysts were loaded into a stainless steel tubular reactor and reduced in $\mathrm{H}_{2} / \mathrm{He}$ mixture (total flow $1.65 \mathrm{~L} \mathrm{~min}^{-1}$ ) $\mathrm{RT}$ to $523 \mathrm{~K}$ at ambient pressure. Following the reduction, the reactor was pressurized to 8 bar in feed gas at $523 \mathrm{~K}$ until a methanol signal was clearly visible in the on-line mass spectrometer. After the products had reached a steady state, the reactor outlet was closed to pressurize it to 20 bar. When the pressure was reached, the heating of the reactor was switched off, to let it cool to $308 \mathrm{~K}$ within $2 \mathrm{~h}$. Afterwards, the reactor was purged with inert gas. The reactor was transferred into a glove box and the catalysts were loaded into an aluminum sachet and placed in a thin-walled, indium-sealed aluminum can. To obtain reasonable resolution across the whole spectral range three incident energies $\left(E_{\mathrm{i}}\right)$ were used: 4840, 2420 and $1210 \mathrm{~cm}^{-1}$. These focus on the $\mathrm{C}-\mathrm{H} / \mathrm{O}-\mathrm{H}$ stretch, the $\mathrm{C}-\mathrm{H}$ deformation and the $\mathrm{O}-\mathrm{H}$ deformation regions respectively. Three spectra were acquired for $4 \mathrm{~h}$ and summed up at each energy. Unless otherwise stated, all the spectra presented of the catalysts are difference spectra: [(catalyst + adsorbate) (reduced catalyst)]. The catalysts, their synthesis and physicochemical characterization has been described in detail previously. ${ }^{2,6,15}$ In the reduced state, CZ and CM exhibit similar specific $\mathrm{Cu}$ surface areas of 14.7 and $13.6 \mathrm{~m}^{2} \mathrm{~g}_{\text {cat }}{ }^{-1}$, respectively, as determined by $\mathrm{H}_{2}$-TPD. ${ }^{35}$

\section{Results}

\section{Methanol formation from $\mathrm{CO} / \mathrm{H}_{2}$}

Fig. 1 shows the exhaust gas composition as a function of time on stream for methanol formation over the CZ, Fig. 1a, and CM catalysts, Fig. 1b. It is clear that $\mathrm{CO}$ forms $\mathrm{CO}_{2}$, presumably by reaction with hydroxyl groups located on the oxide ( $\mathrm{ZnO}$ or $\mathrm{MgO})$, as in the case of hydrous palladium oxide. ${ }^{19}$

$$
\mathrm{CO}+2 \mathrm{OH} \rightarrow \mathrm{H}_{2} \mathrm{O}+\mathrm{CO}_{2}
$$

The presence of hydroxyls is seen in the INS spectra of the reduced catalysts before methanol synthesis occurs, Fig. 2. 

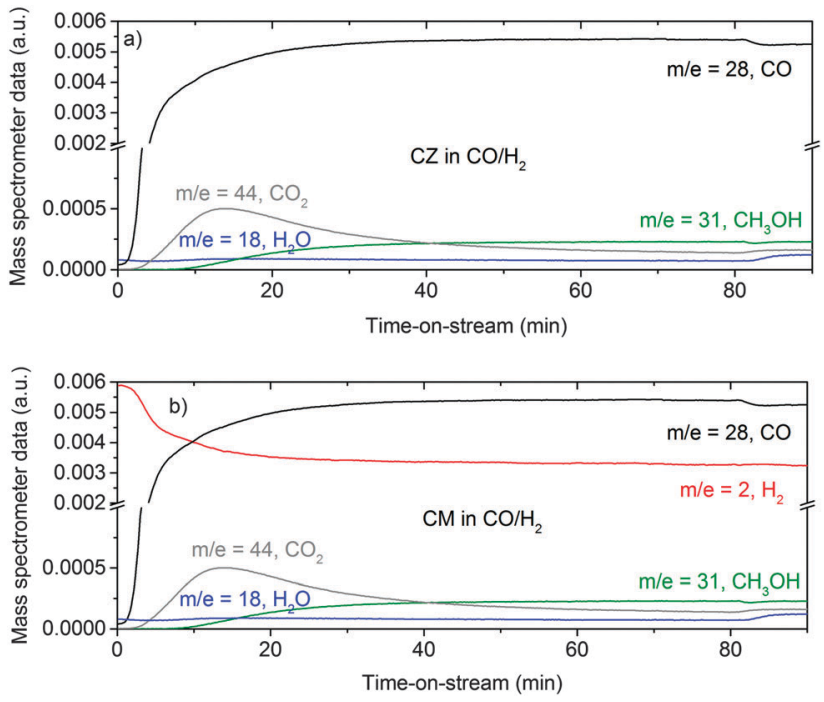

Fig. 1 Gas analysis during methanol synthesis at 6.31 bar and $523 \mathrm{~K}$ over the $\mathrm{CZ}$ (a) and $\mathrm{CM}$ (b) catalyst in $\mathrm{CO} / \mathrm{H}_{2}$ feed gas (composition: $37.5 \mathrm{ml} \mathrm{min}{ }^{-1} \mathrm{CO}, 150 \mathrm{ml} \mathrm{min}{ }^{-1} \mathrm{H}_{2}$ and $1500 \mathrm{ml} \mathrm{min}{ }^{-1} \mathrm{He}$ ). Due to a technological problem, the $\mathrm{m} / \mathrm{z}=2$ trace in (a) is erroneous and not shown. The true evolution of the hydrogen concentration is expected to be similar to the trace shown in (b).

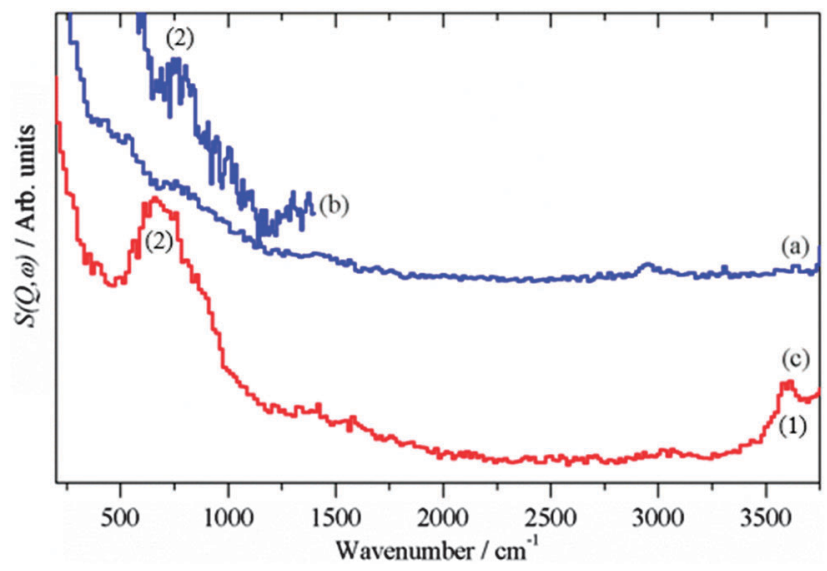

Fig. 2 INS spectra of the reduced catalysts before methanol synthesis was carried out. (a) $\mathrm{Cu} / \mathrm{ZnO}\left(E_{\mathrm{i}}=4840 \mathrm{~cm}^{-1}\right)$ (b) $\mathrm{Cu} / \mathrm{ZnO}\left(E_{\mathrm{i}}=2420 \mathrm{~cm}^{-1}\right)$ and (c) $\mathrm{Cu} / \mathrm{MgO}\left(E_{\mathrm{i}}=4840 \mathrm{~cm}^{-1}\right)$. (a) and (c) are plotted on the same ordinate scale.

The assignments of INS bands encountered in this study are compiled in Table 1.

For the reduced $\mathrm{CZ}$ catalyst Fig. 2a, there are too few hydroxyls to allow detection of the $\mathrm{O}-\mathrm{H}$ stretch, however, the stronger bending mode at $760 \mathrm{~cm}^{-1}$ is seen, Fig. $2 \mathrm{~b}$. For the CM catalyst Fig. 2c, the much higher density of hydroxyls enables both the stretch $\left(3600 \mathrm{~cm}^{-1}\right)$ and bend $\left(690 \mathrm{~cm}^{-1}\right)$ to be observed. Close inspection of Fig. 1a and b shows an increase in the water signal simultaneously with the $\mathrm{CO}_{2}$ spike, consistent with eqn (15).

Fig. 3 shows the background subtracted spectra of the catalysts (CZ Fig. 3a and CM Fig. 3b) after methanol synthesis in $\mathrm{CO} / \mathrm{H}_{2}$ at 6.31 bar and $523 \mathrm{~K}$. For comparison, the spectrum of solid methanol is also shown Fig. 3c. For the CZ catalyst, strong features are seen at 2940,1450, 1160 and $95 \mathrm{~cm}^{-1}$. These are assigned as the $\mathrm{C}-\mathrm{H}$ stretch, the $\mathrm{C}-\mathrm{H}$ deformations, methyl rock and methyl torsion respectively of chemisorbed methoxy. ${ }^{20,21}$ These can be unambiguously assigned to methoxy rather than physisorbed methanol by the absence of the features relating to the O-H group of methanol: the $\mathrm{O}-\mathrm{H}$ stretch at $3200 \mathrm{~cm}^{-1}$ and the $\mathrm{C}-\mathrm{O}-\mathrm{H}$ bend at $750 \mathrm{~cm}^{-1}$, that are seen in the reference spectrum, Fig. 3c. The same features are also seen for the CM catalyst, Fig. $3 \mathrm{~b}$, although there are additional features that are due to surface hydroxyls, $c f$. Fig. 2c, generated in the reaction. The hydroxyl bending mode occurs in the same region as the methanol $\mathrm{C}-\mathrm{O}-\mathrm{H}$ bend mode, so complicates the distinction between methoxy and physisorbed methanol. However, the shape of the C-H stretch on the CM catalyst at $2940 \mathrm{~cm}^{-1}$ is very similar to that seen on the $\mathrm{CZ}$ catalyst and distinctly different to the overlapping $\mathrm{C}-\mathrm{H}$ and $\mathrm{O}-\mathrm{H}$ stretch modes of solid methanol. Thus it is highly probable that methoxy is the dominant species on the CM catalyst as well. Methoxy typically adsorbs in an on-top mode on copper single crystal surfaces, ${ }^{36-38}$ but might be found in a bridged form on the supposedly important step sites as suggested by DFT. ${ }^{6}$

\section{Methanol formation from $\mathrm{CO}_{2} / \mathrm{H}_{2}$}

Fig. 4 shows the evolution of the product gas concentrations, $\mathrm{CO}$ as a product of the reverse water gas shift reaction and methanol and water as products of methanol synthesis from $\mathrm{CO}_{2}$, as a function of time on stream over the CZ, Fig. 4a, and CM catalysts, Fig. 4b. Unfortunately, there were experimental difficulties, so the profiles are not as clean as for the $\mathrm{CO} / \mathrm{H}_{2}$ reaction, nonetheless, methanol formation is clearly observed over both catalysts. In good agreement with previous kinetic studies, ${ }^{2,15}$ the methanol productivity of the CM catalyst however is much lower than CZ. CM rather produces CO from the reverse water gas shift. This behaviour has been related to the absence of SMSI in this catalyst and its inability to convert formate to methanol in the absence of $\mathrm{Zn}^{15}$

Fig. 5 shows the background subtracted spectra of the catalysts (CZ Fig. 5a and CM Fig. 5b) after methanol synthesis in $\mathrm{CO}_{2} / \mathrm{H}_{2}$ at 6.31 bar and $523 \mathrm{~K}$. A reference spectrum of $\mathrm{Cu}(\mathrm{HCOO})_{2} \cdot 4 \mathrm{H}_{2} \mathrm{O}$ is also shown, Fig. 5 c. For both catalysts, features are again seen at 2940, 1450, 1160 and $95 \mathrm{~cm}^{-1}$. As before, these are assigned to chemisorbed methoxy rather than physisorbed methanol, the downshift of the torsional mode from $110 \mathrm{~cm}^{-1}$ in methanol to $95 \mathrm{~cm}^{-1}$ in the chemisorbed species supports this assignment.

In contrast to the reaction in $\mathrm{CO} / \mathrm{H}_{2}$, formate is also present on the surface. Both catalysts show the characteristic ${ }^{22,23}$ in-plane $\mathrm{C}-\mathrm{H}$ deformation mode at $1375 \mathrm{~cm}^{-1}$, the weaker out-of-plane deformation is just visible at $1055 \mathrm{~cm}^{-1}$ in the CZ sample, Fig. 5a. Unfortunately, the mode of formate coordination (mono- or bidentate) cannot be distinguished here as the diagnostic modes are the symmetric and asymmetric $\mathrm{C}-\mathrm{O}$ stretches which are invisible to INS. A second difference between the reactions is the $\mathrm{CZ}$ sample shows the presence of hydroxyls, bands at 3430 and $915 \mathrm{~cm}^{-1}$ for the $\mathrm{O}-\mathrm{H}$ stretch and bend respectively. No clear indication of adsorbed water is seen 
Table 1 Observed bands of the adsorbed species and their assignment

\begin{tabular}{|c|c|c|c|}
\hline \multirow[b]{2}{*}{ Process } & \multicolumn{2}{|l|}{ Catalyst } & \multirow[b]{2}{*}{ Assignment (mark in fig.) } \\
\hline & $\mathrm{CZ} / \mathrm{cm}^{-1}$ & $\mathrm{CM} / \mathrm{cm}^{-1}$ & \\
\hline After reduction (Fig. 2) & & 3600 & $\mathrm{O}-\mathrm{H}$ stretch of surface hydroxyl on the metal oxide (1) \\
\hline \multirow[t]{4}{*}{$\mathrm{CO} / \mathrm{H}_{2}$ (Fig. 3) } & & 3600 & $\mathrm{O}-\mathrm{H}$ stretch of surface hydroxyl on $\mathrm{MgO}$ (1) \\
\hline & 2940 & 2940 & C-H stretch of adsorbed methoxy (2) \\
\hline & 1460 & 1460 & OC-H bending modes of adsorbed methoxy (3) \\
\hline & 95 & 95 & Methyl torsion of adsorbed methoxy (6) \\
\hline \multirow[t]{5}{*}{$\mathrm{CO}_{2} / \mathrm{H}_{2}$ (Fig. 5) } & & 3600 & $\mathrm{O}-\mathrm{H}$ stretch of surface hydroxyl on $\mathrm{MgO}$ (1) \\
\hline & 3430 & & $\mathrm{O}-\mathrm{H}$ stretch of surface hydroxyl on $\mathrm{Cu}(2)$ \\
\hline & 2970 & 2970 & C-H stretch of adsorbed methoxy and formate (3) \\
\hline & 1450 & 1450 & OC-H bending modes of adsorbed methoxy (4) \\
\hline & 95 & 95 & Methyl torsion of adsorbed methoxy (10) \\
\hline
\end{tabular}

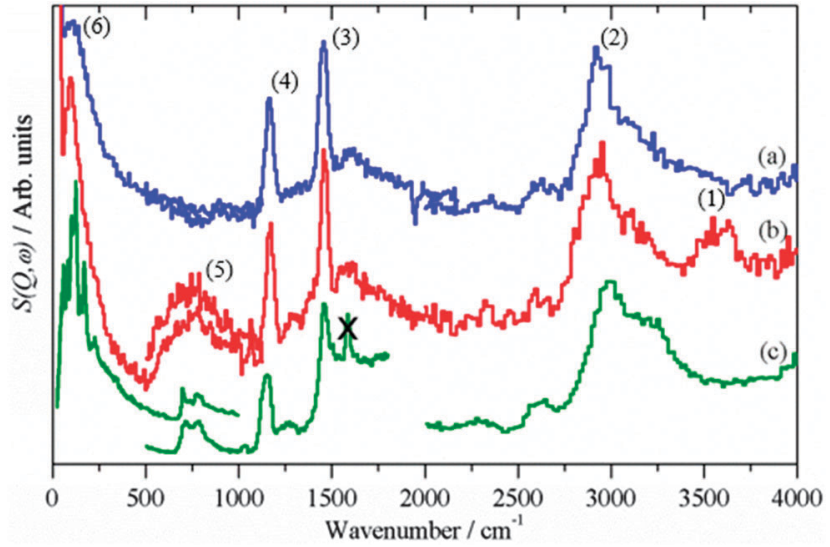

Fig. 3 Difference INS spectra after methanol synthesis in $\mathrm{CO} / \mathrm{H}_{2}$ : (a) $\mathrm{CZ}$, (b) CM. (c) Reference spectrum of solid methanol. The region $4000-2000 \mathrm{~cm}^{-1}$ was recorded with $E_{\mathrm{i}}=4840 \mathrm{~cm}^{-1}, 2000-500 \mathrm{~cm}^{-1}$ with $E_{\mathrm{i}}=2420 \mathrm{~cm}^{-1}$ and $500-0 \mathrm{~cm}^{-1}$ with $E_{\mathrm{i}}=1210 \mathrm{~cm}^{-1}$, except for the $500-0 \mathrm{~cm}^{-1}$ region of solid methanol which was recorded with TOSCA and the spectrum obtained from the INS database at: http://wwwisis2.isis.rl.ac.uk/INSdatabase/. The feature marked by $X$ is an instrumental artefact.

in the spectra, but its presence cannot be unambiguously excluded and a small amount of water might be present.

\section{Discussion}

This work shows a clear distinction between the catalysts and different behaviour depending on the feedstock for methanol synthesis. Chemisorbed methoxy is observed in all cases, although the quantity varies considerably: $\mathrm{CZ}\left(\mathrm{CO} / \mathrm{H}_{2}\right) \approx \mathrm{CM}\left(\mathrm{CO} / \mathrm{H}_{2}\right)=2.5$ $\mathrm{CM}\left(\mathrm{CO}_{2} / \mathrm{H}_{2}\right)=2 \mathrm{CZ}\left(\mathrm{CO}_{2} / \mathrm{H}_{2}\right)$. This indicates that the methoxy is bonded to the copper in all cases. The spectra from the $\mathrm{CO} / \mathrm{H}_{2}$ reaction represent a saturated monolayer on the catalyst that with the similar copper areas for both $\mathrm{CZ}$ and CM give similar
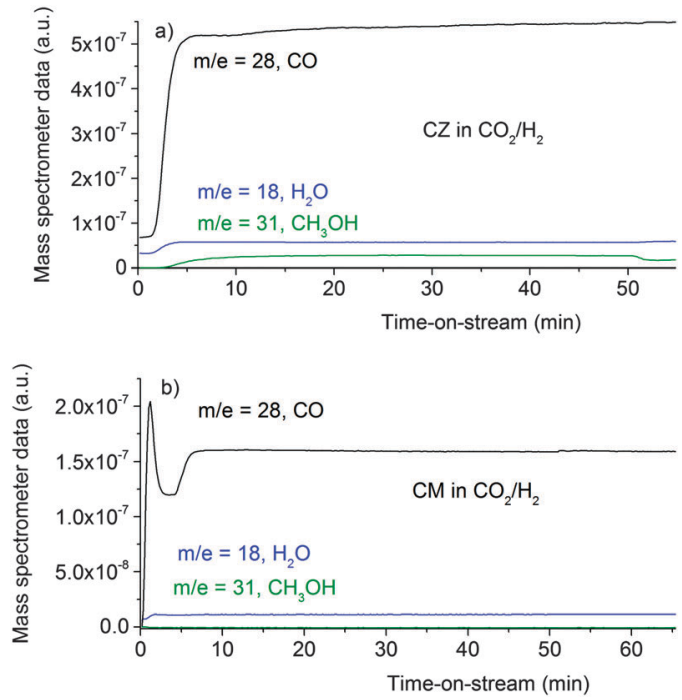

Fig. 4 Product analysis during methanol synthesis at 6.31 bar and $523 \mathrm{~K}$ over the $\mathrm{CZ}$ catalyst (a) and the $\mathrm{CM}$ catalyst (b) in $\mathrm{CO}_{2} / \mathrm{H}_{2}$ feed gas (composition: $37.5 \mathrm{ml} \mathrm{min}^{-1} \mathrm{CO}_{2}, 150 \mathrm{ml} \mathrm{min}^{-1} \mathrm{H}_{2}$ and $1500 \mathrm{ml} \mathrm{min}{ }^{-1} \mathrm{He}$ ).

intensities as there is no other species present on the catalyst, (the similarity of the hydroxyl spectra on CM before and after reaction shows that they are on the $\mathrm{MgO}$ ). For the $\mathrm{CO}_{2} / \mathrm{H}_{2}$ reaction this is not the case and an additional species, formate, competes for space, again suggesting that the formate is on the copper. For the CM catalyst the total area of (methoxy + formate) $\approx$ (methoxy) for the $\mathrm{CO}_{2} / \mathrm{H}_{2}$ and $\mathrm{CO} / \mathrm{H}_{2}$ processes respectively, supporting the idea of adsorption on the copper.

For the $\mathrm{CZ}$ catalyst in $\mathrm{CO}_{2} / \mathrm{H}_{2}$ the area occupied by the two carbonaceous intermediates is different in the two reactions, the combined area is less than half that of the $\mathrm{CO} / \mathrm{H}_{2}$. In addition to formate, hydroxyls are also seen at 3460 and $920 \mathrm{~cm}^{-1}$ for the $\mathrm{O}-\mathrm{H}$ stretch and bend respectively, these do 


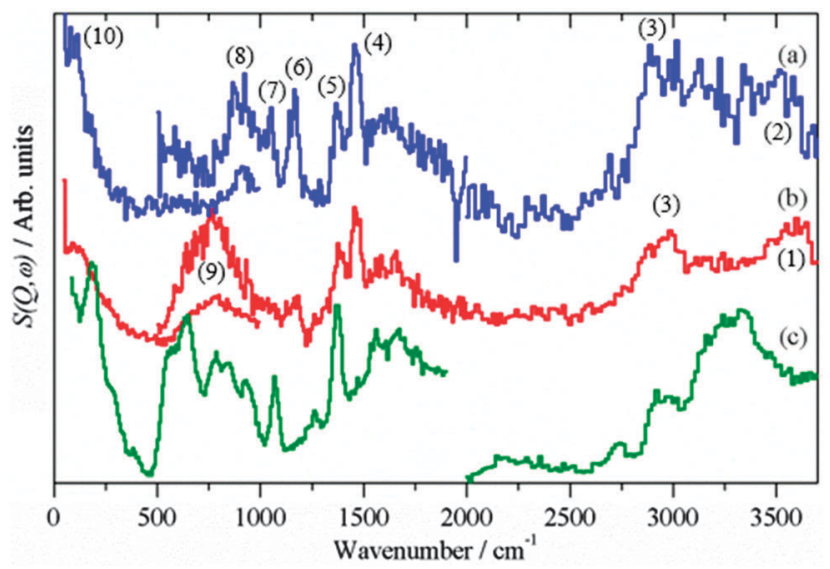

Fig. 5 Difference INS spectra after methanol synthesis in $\mathrm{CO}_{2} / \mathrm{H}_{2}$ : (a) $\mathrm{CZ}$, (b) $\mathrm{CM}$. (c) Reference spectrum of $\mathrm{Cu}(\mathrm{HCOO})_{2} \cdot 4 \mathrm{H}_{2} \mathrm{O}$. The region $4000-2000 \mathrm{~cm}^{-1}$ was recorded with $E_{\mathrm{i}}=4840 \mathrm{~cm}^{-1}, 2000-500 \mathrm{~cm}^{-1}$ with $E_{\mathrm{i}}=2420 \mathrm{~cm}^{-1}$ and $500-0 \mathrm{~cm}^{-1}$ with $E_{\mathrm{i}}=1210 \mathrm{~cm}^{-1}$.

not occur for the reaction under $\mathrm{CO} / \mathrm{H}_{2}$. The position of the bending mode is significantly higher than was found for hydroxyls on the ZnO support, Fig. 2b. Comparison with hydroxyls in $\mathrm{Cu}(\mathrm{OH})_{2}$ and on RANEY ${ }^{\mathbb{R}} \mathrm{Cu}$, Fig. 6, shows that the hydroxyl bending mode for the $\mathrm{CZ}$ catalyst occurs in the region found for $\mathrm{OH}$ bonded to $\mathrm{Cu}$. Together with the reduced total area of (methoxy + formate), this suggests that the hydroxyls are on the $\mathrm{Cu}$ component of the catalyst, rather than on the ZnO support, which is consistent with the observed product inhibition by the coupled product $\mathrm{H}_{2} \mathrm{O}$ during methanol synthesis from $\mathrm{CO}_{2}$ on $\mathrm{Cu} / \mathrm{ZnO}$ catalysts. ${ }^{39}$

As described in the Introduction, methanol synthesis has been the subject of extensive theoretical work. ${ }^{6,15}$ Fig. 7 shows the Gibbs free energy calculated by DFT for the $\mathrm{CO} / \mathrm{H}_{2}$, Fig. 7a, and the $\mathrm{CO}_{2} / \mathrm{H}_{2}$, Fig. $7 \mathrm{~b}$, reactions. ${ }^{15}$ Our results are completely consistent with this model. For the $\mathrm{CO} / \mathrm{H}_{2}$ reaction, it can be

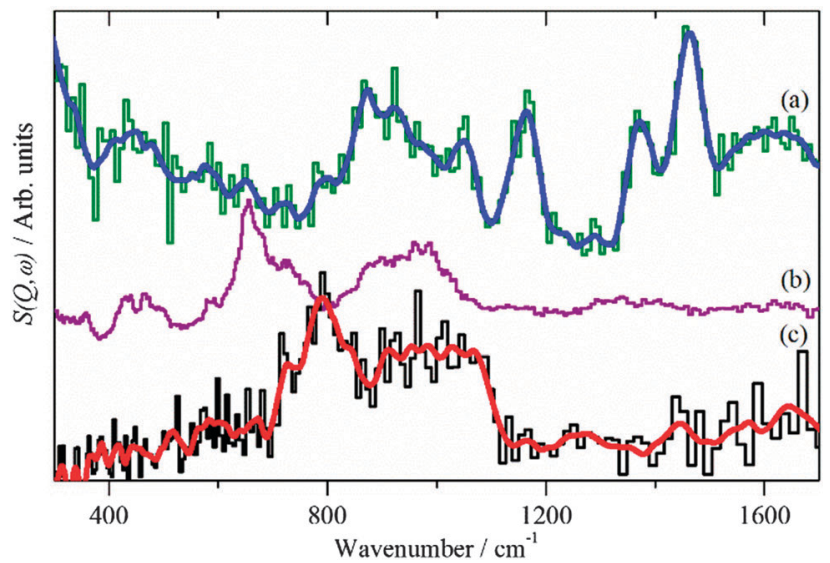

Fig. 6 (a) Difference INS spectrum of $\mathrm{Cu} / \mathrm{ZnO}$ after methanol synthesis in $\mathrm{CO}_{2} / \mathrm{H}_{2}\left(E_{\mathrm{i}}=2420 \mathrm{~cm}^{-1}\right)$. Reference spectra of: (b) $\mathrm{Cu}(\mathrm{OH})_{2}$ (Aldrich) and (c) hydroxyls on RANEY ${ }^{\mathbb{R}} \mathrm{Cu}$ (dried at $120^{\circ} \mathrm{C}$ in flowing He). The blue and red lines are the smoothed raw spectra. (b) and (c) were recorded at $20 \mathrm{~K}$ on TOSCA. In this region the instruments provide very similar spectra, thus all the spectra may be directly compared.

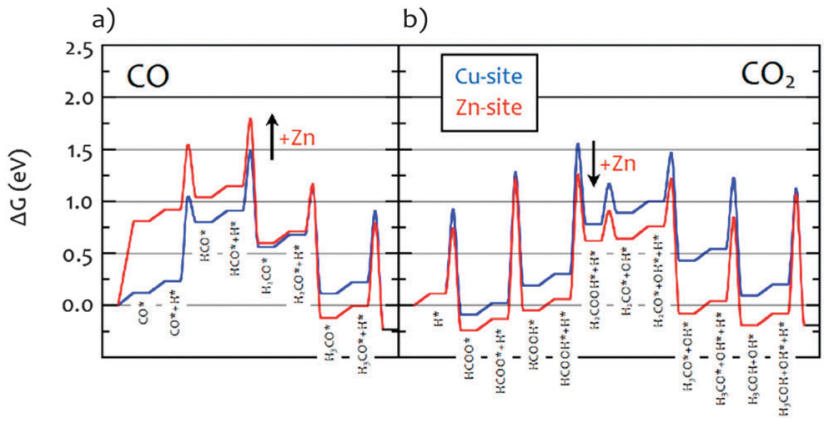

Fig. 7 Gibbs free energy diagram obtained from DFT calculations ${ }^{15}$ for the reaction under: (a) $\mathrm{CO} / \mathrm{H}_{2}$ and (b) $\mathrm{CO}_{2} / \mathrm{H}_{2}$ on stepped $\mathrm{Cu}(211)$, blue "Cu-site" representing $\mathrm{CM}$, and a $\mathrm{Zn}$-decorated steps $\mathrm{CuZn(211),}$ red "Zn-site" representing $C Z$. Zn substitution was modeled by replacing all step atoms of $\mathrm{Cu}(211)$ with $\mathrm{Zn}$. All energies are relative to $\mathrm{CO}_{2}+3 \mathrm{H}_{2}$ $\left(\mathrm{CO}+2 \mathrm{H}_{2}\right)$ in the gas phase and the clean surfaces. Intermediates marked with a star are adsorbed on the surface. Gibbs free energies were calculated at $T=503 \mathrm{~K}$ and a total $\mathrm{P}$ of $30 \mathrm{bar}$

seen that on both the $\mathrm{Cu}$-only and the $\mathrm{Cu}-\mathrm{Zn}$ surfaces the only stable hydrogenous intermediate is methoxy. In contrast, for the $\mathrm{CO}_{2} / \mathrm{H}_{2}$ reaction, both formate and methoxy are stable intermediates. The calculations also show that hydroxyls should be present on the metal surface, these are seen for the $\mathrm{CZ}$ catalyst but not for the CM, presumably these are more stable on the $\mathrm{MgO}$ and so spillover onto the $\mathrm{MgO}$. It is noted that a kinetic model calculated for differential conversion showed formate to be the only dominating surface species on CZ. ${ }^{15}$ The is due to the stronger bonding compared to the other intermediates and the overall lower amount of the product-like intermediate methoxy under such conditions. Thus, co-adsorption is characterized by a competition between hydroxyl and methoxy with formate and the coverage will depend on the chemical potentials given be the pressure and conversion. In this experiment, due to the closure of the exhaust gas stream and the build-up of pressure before the INS measurements, we are likely away from differential conversions explaining the observed substantial amount of methoxy and hydroxyls compared to previous kinetic modelling.

\section{Conclusions}

We have investigated methanol synthesis with model supported copper catalysts using $\mathrm{CO} / \mathrm{H}_{2}$ and $\mathrm{CO}_{2} / \mathrm{H}_{2}$ as feedstocks. Under $\mathrm{CO} / \mathrm{H}_{2}$ both catalysts show chemisorbed methoxy as a stable intermediate, the $\mathrm{CM}$ catalyst also shows hydroxyls on the support. Under $\mathrm{CO}_{2} / \mathrm{H}_{2}$ the catalysts behave differently, in that formate is also seen on the catalyst. For the $\mathrm{CZ}$ catalyst hydroxyls are present on the metal whereas for the CM material hydroxyls are found on the support. These results are consistent with a recently published model $^{2}$ for methanol synthesis, in which reduced $\mathrm{Zn}$ species on stepped copper surfaces are responsible to the hydrogenation of formate to methanol copper and, thus, highlight the key role of $\mathrm{ZnO}$ in the process. 


\section{Acknowledgements}

The authors would like to thank Julia Schumann, Stefan Zander, Nygil Thomas and Florian Ribicki for sample preparation, discussions and assistance. The STFC Rutherford Appleton Laboratory is acknowledged for the allocation of neutron beam time. This research project has been supported by the European Commission under the 7th Framework Programme, NMI3-II Grant number 283883, CP-CSA_INFRA-2008-1.1.1.

\section{References}

1 B. Denise and R. P. A. Sneeden, Appl. Catal., 1986, 28, 235-239.

2 S. Zander, E. L. Kunkes, M. E. Schuster, J. Schumann, G. Weinberg, D. Teschner, N. Jacobsen, R. Schlögl and M. Behrens, Angew. Chem., Int. Ed., 2013, 52, 6536-6540.

3 Y. Choi, K. Futagami, T. Fujitani and J. Nakamura, Appl. Catal., A, 2001, 208, 163-167.

4 R. Burch, S. E. Golunski and M. S. Spencer, J. Chem. Soc., Faraday Trans., 1990, 86, 2683-2691.

5 L. C. Grabow and M. Mavrikakis, ACS Catal., 2011, 1, 365-384. 6 M. Behrens, F. Studt, I. Kasatkin, S. Kühl, M. Hävecker, F. Abild-Pedersen, S. Zander, F. Girgsdies, P. Kurr, B.-L. Kniep, M. Tovar, R. W. Fischer, J. K. Nørskov and R. Schlögl, Science, 2012, 336, 893-897.

7 Z.-J. Zuo, L. Wang, P.-D. Han and W. Huang, Appl. Surf. Sci., 2014, 290, 398-404.

8 H. H. Kung, Catal. Rev., 1980, 22, 235-259.

9 K. Klier, in Advances in Catalysis, ed. H. P. D. D. Eley and B. W. Paul, Academic Press, 1982, vol. 31, pp. 243-313.

10 G. C. Chinchen, P. J. Denny, D. G. Parker, M. S. Spencer and D. A. Whan, Appl. Catal., 1987, 30, 333-338.

11 A. Deluzarche, R. Kieffer and A. Muth, Tetrahedron Lett., 1977, 18, 3357-3360.

12 J. B. Hansen and P. E. Højlund Nielsen, Handbook of Heterogeneous Catalysis, Wiley-VCH Verlag $\mathrm{GmbH} \& \mathrm{Co}$. KGaA, 2008, DOI: 10.1002/9783527610044.hetcat0148.

13 G. A. Olah, A. Goeppert and G. K. S. Prakash, Beyond oil and gas: the methanol economy, Wiley-VCH, Weinheim an der Bergstrasse, Germany, 2006.

14 M. Ruggiero and G. Manfrida, Renewable Energy, 1999, 16, 1106-1109.

15 F. Studt, M. Behrens, E. L. Kunkes, N. Thomas, S. Zander, A. Tarasov, J. Schumann, E. Frei, J. B. Varley, F. AbildPedersen, J. K. Nørskov and R. Schlögl, ChemCatChem, 2015, 7, 1105-1111.

16 M. Bowker, R. A. Hadden, H. Houghton, J. N. K. Hyland and K. C. Waugh, J. Catal., 1988, 109, 263-273.

17 R. N. d'Alnoncourt, X. Xia, J. Strunk, E. Loffler, O. Hinrichsen and M. Muhler, Phys. Chem. Chem. Phys., 2006, 8, 1525-1538.

18 T. Lunkenbein, J. Schumann, M. Behrens, R. Schlögl and M. G. Willinger, Angew. Chem., 2015, 127, 4627-4631.

19 T. Kandemir, F. Girgsdies, T. C. Hansen, K.-D. Liss, I. Kasatkin, E. L. Kunkes, G. Wowsnick, N. Jacobsen,
R. Schlögl and M. Behrens, Angew. Chem., Int. Ed., 2013, 52, 5166-5170.

20 P. A. Taylor, P. B. Rasmussen, C. V. Ovesen, P. Stoltze and I. Chorkendorff, Surf. Sci., 1992, 261, 191-206.

21 I. Chorkendorff, P. A. Taylor and P. B. Rasmussen, J. Vac. Sci. Technol., A, 1992, 10, 2277-2281.

22 J. Howard, I. J. Braid and J. Tomkinson, J. Chem. Soc., Faraday Trans. 1, 1984, 80, 225-235.

23 V. A. Trunov, A. E. Sokolov, V. T. Lebedev, O. P. Smirnov, A. I. Kurbakov, J. Van den Heuvel, E. Batyrev, T. M. Yurieva, L. M. Plyasova and G. Török, Phys. Solid State, 2006, 48, 1291-1297.

24 C. H. Rochester, Catal. Lett., 1998, 52, 121.

25 N.-Y. Topsøe and H. Topsøe, J. Mol. Catal. A: Chem., 1999, 141, 95-105.

26 A. R. McInroy, D. T. Lundie, J. M. Winfield, C. C. Dudman, P. Jones, S. F. Parker, J. W. Taylor and D. Lennon, Phys. Chem. Chem. Phys., 2005, 7, 3093-3101.

27 A. A. Khassin, H. Jobic, G. A. Filonenko, E. V. Dokuchits, A. V. Khasin, T. P. Minyukova, N. V. Shtertser, L. M. Plyasova and T. M. Yurieva, J. Mol. Catal. A: Chem., 2013, 373, 151-160.

28 S. Bailey, G. F. Froment, J. W. Snoeck and K. C. Waugh, Catal. Lett., 1994, 30, 99-111.

29 S. F. Parker, D. Lennon and P. W. Albers, Appl. Spectrosc., 2011, 65, 1325-1341.

30 D. Lennon, D. T. Lundie, S. D. Jackson, G. J. Kelly and S. F. Parker, Langmuir, 2002, 18, 4667-4673.

31 A. R. McInroy, D. T. Lundie, J. M. Winfield, C. C. Dudman, P. Jones, S. F. Parker and D. Lennon, Catal. Today, 2006, 114, 403-411.

32 A. R. McInroy, D. T. Lundie, J. M. Winfield, C. C. Dudman, P. Jones, S. F. Parker, J. W. Taylor and D. Lennon, Phys. Chem. Chem. Phys., 2005, 7, 3093-3101.

33 P. W. Albers and S. F. Parker, Applications of neutron scattering in the chemical industry: proton dynamics of highly dispersed materials, characterization of fuel cell catalysts and catalysts from large-scale chemical processes, in Neutron Applications in Earth, Energy and Environmental Sciences, ed. L. Liang, R. Rinaldi and H. Schober, Springer, 2009, pp. 391-416.

34 P. C. H. Mitchell, S. F. Parker, A. J. Ramirez-Cuesta and J. Tomkinson, Vibrational Spectroscopy with Neutrons: With Applications in Chemistry, Biology, Materials Science and Catalysis, World Scientific, 2005.

35 M. B. Fichtl, J. Schumann, I. Kasatkin, N. Jacobsen, M. Behrens, R. Schlögl, M. Muhler and O. Hinrichsen, Angew. Chem., 2014, 126, 7163-7167.

36 J. P. Camplin and E. M. McCash, Surf. Sci., 1996, 360, 229-241.

37 M. A. Chesters and E. M. McCash, Spectrochim. Acta, Part A, 1987, 43, 1625-1630.

38 K. Mudalige and M. Trenary, Surf. Sci., 2002, 504, 208-214. 39 M. Sahibzada, I. S. Metcalfe and D. Chadwick, J. Catal., 1998, 174, 111-118. 